\title{
Análise experimental de consolos instalados em etapa posterior à concretagem de pilar com auxílio de adesivo químico
}

\author{
Experimental analysis of post-installed corbels \\ with adhesive anchors
}

\author{
Joao Henrique Lannes Damasceno ${ }^{1}$, Bruna Catoia ${ }^{1}$, \\ Marcelo de Araujo Ferreira ${ }^{1}$
}

\begin{abstract}
${ }^{1}$ Núcleo de Estudo e Tecnologia em Pré-moldados de Concreto (NETPre). Departamento de Engenharia Civil da Universidade Federal de São Carlos - Deciv/UFSCar, Rod. Washington Luis, km 235 - São Carlos, SP CEP:13565-905. e-mail: joaohenriqueld@gmail.com, bcatoia@yahoo.com.br, marceloaferreira@uol.com.br
\end{abstract}

\begin{abstract}
RESUMO
A maior dificuldade no emprego das estruturas pré-moldadas está relacionada com as ligações, que podem ser complexas e custosas, dependendo do projeto, contrapondo-se a uma das principais vantagens desse sistema construtivo, a rapidez. Assim, a busca por soluções mais simples e econômicas corresponde a um dos princípios mais importantes do projeto. Diante deste contexto, uma das alternativas a ser considerada durante o projeto, visando melhorar a simplicidade na produção de pilares, é evitar furos e saliências nas fôrmas com elevado custo. O principal objetivo deste trabalho é estudar a alternativa de utilizar adesivos químicos para a instalação das barras que compõem a armadura realizando a concretagem do consolo em etapa posterior à execução do pilar. Foi desenvolvido um programa experimental no qual foram ensaiados três modelos em escala real com consolo curto de mesmas dimensões, dois consolos com armadura do tirante ancorada por meio de ancoragem química e um consolo monolítico com armadura ancorada por meio de gancho dobrado a $90^{\circ}$. O consolo monolítico (modelo A) foi projetado atendendo aos requisitos das normas NBR 6118:2014 e NBR 9062:2006. Um modelo (modelo B) com ancoragem química foi projetado com o mesmo comprimento de ancoragem do modelo monolítico e outro modelo (modelo C) com ancoragem química foi projetado conforme as recomendações do fabricante do adesivo químico. Desta forma, foi possível avaliar, através da comparação entre os modelos, que o comprimento de ancoragem não apresentou influência no comportamento dos consolos pós-instalados. O modelo A apresentou carga última de $400 \mathrm{kN}$, o modelo B de $340 \mathrm{kN}$ e o modelo $\mathrm{C}$ de $377 \mathrm{kN}$. Todos os modelos apresentaram ruptura por tração na flexão de forma dúctil e cargas últimas maiores que o previsto por normas e modelos de cálculo. Assim, constatou-se que os consolos pósinstalados apresentaram comportamento mecânico satisfatório, podendo ser considerado como uma solução viável.
\end{abstract}

Palavras-chave: Ancoragens químicas, concreto pré-moldado, ligações, consolos.

\section{ABSTRACT}

The greater difficulty in the use of precast structures is related to the connections, which can be complex and costly depending on the design, opposing one of the main advantages of this constructive system, the speed. Then, the search for simpler and more economical solutions corresponds to one of the most important principles of the project. Thus, one of the alternatives to be considered during the project to improve the simplicity in the column production is to avoid holes and cuts in the formwork. The main aim of this paper is to study the alternative of using chemical adhesive for fastening the corbel reinforcement after casting the column. It was developed an experimental program with 3 tests full scale specimens with equal dimensions short corbels. Were tested 2 post-installed corbels with the main tie reinforcement fastened with adhesive anchor and 1 cast in corbel with the main tie reinforcement anchored with hooked $90^{\circ}$ bars. The cast in corbel (specimen A) was designed according to the recommendations of the standards NBR6118:2014 e NBR9062:2006, 1 post-installed corbel (specimen B) was designed with the same anchorage length of the cast in corbel and the other post-installed corbel was designed according to the recommendations of the chemical adhesive produc- 
er. This way, was possible evaluate by comparing the models that the anchorage length did not influence the corbel behavior during the test. The specimen A presented the ultimate load of $400 \mathrm{kN}$, specimen B $340 \mathrm{kN}$ and specimen $\mathrm{C} 377 \mathrm{kN}$ was possible evaluate the influence of the anchorage length in the corbel behavior and the safety of the solution comparing with a cast in corbel. All of the specimens presented failure by flexure-tension in a ductile manner and ultimate loads higher than foreseen by standards and calculation models. The post-installed corbels presented a satisfactory mechanical behavior and can be considered as a viable alternative.

Keywords: Adhesive anchors, precast concrete, connections, corbels.

\section{INTRODUÇÃO}

Um dos princípios mais importantes no projeto de ligações é a busca contínua por soluções simples. A máxima economia em uma construção pré-moldada é atingida quando os elementos de ligação são simples, com um desempenho adequado e com uma montagem rápida. Uma das alternativas a ser considerada durante o projeto, visando melhorar a simplicidade na produção de pilares, é evitar furos e saliências nas fôrmas. Projeções que requerem furos e recortes nas fôrmas são trabalhosas e reduzem sua vida útil.

Um dos tipos mais utilizados para ligação entre viga e pilar pré-moldado são os consolos, saliências nos pilares para que a viga se apoie e transmita a carga para o pilar. Os consolos são elementos muito utilizados que exigem cuidado no dimensionamento e arranjo das barras que compõem a armadura. Quando produzidos na mesma etapa de concretagem do pilar, exigem que a forma deste apresente saliências para abrigá-los, sendo comum a existência de recortes na forma e o congestionamento de barras de armadura na região do consolo.

A repetição e o reaproveitamento de formas na produção de elementos pré-moldados são itens de suma importância. Muitas vezes o recorte na forma para o consolo impossibilita este reaproveitamento, o que faz com que a indústria de pré-fabricados busque alternativas na confecção de pilares visando uma maior produtividade.

Nos últimos anos a utilização de ancoragens químicas teve muito crescimento na construção civil em razão do aumento de aplicações possíveis. Na Figura 1 pode-se observar algumas aplicações da ancoragem química na construção civil.
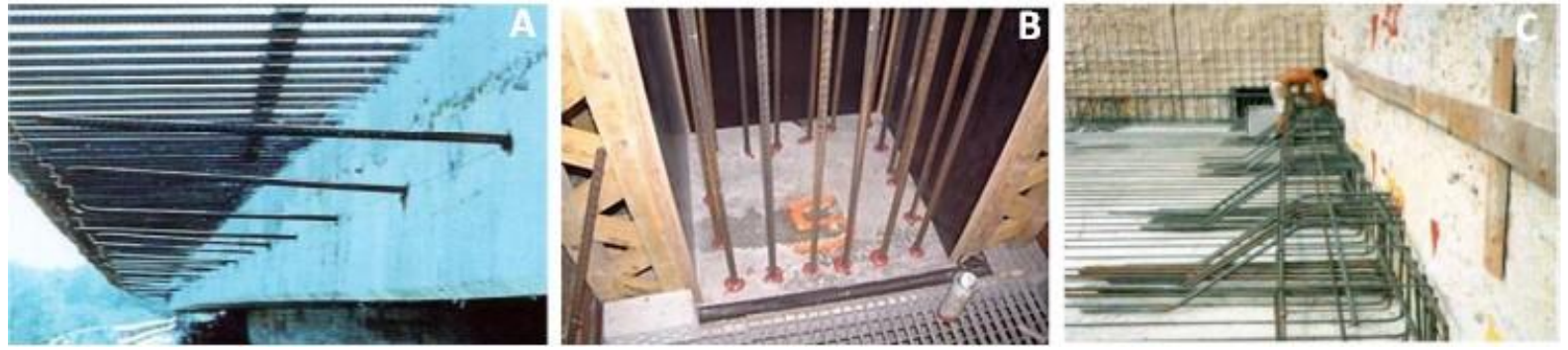

Figura 1: Aplicações da ancoragem química na construção civil. A) Ampliação de uma laje; B) Inserção de barras de espera; C) Conexão de laje com parede diafragma. (Fonte: adaptado de [1]).

Atualmente elas são utilizadas no reparo e reforma de estruturas existentes, ampliação de lajes, inserção de barras de espera, conexão de lajes com parede diafragma, além de construção de novas estruturas.

\subsection{Objetivo e justificativa}

Este trabalho tem como objetivo principal avaliar o comportamento e a segurança de consolos curtos instalados em etapa posterior à execução de pilar com auxílio de adesivo químico. As análises foram feitas através da comparação de um consolo monolítico calculado com duas normas vigentes no cenário nacional: NBR 6118 [2] e NBR 9062 [3].

A proposta de execução do consolo com auxílio de adesivo químico em etapa posterior ao pilar corresponde a uma alternativa para o processo produtivo de pilares com consolos visando a busca por soluções mais simples, em relação ao comumente utilizado. Esta alternativa é vantajosa, pois evita recortes nas formas, possibilitando maior reaproveitamento e também maior flexibilidade ao projeto, uma vez que o consolo pode ser instalado em qualquer altura do pilar. Deste modo, justifica-se este trabalho em vista do avanço no pro- 
cesso produtivo e flexibilidade que esta proposta pode trazer.

\subsection{Ancoragens químicas}

Ancoragens químicas são barras de aço inseridas em furos realizados em concreto endurecido (já curado) embebidas por um fluido responsável pela adesão entre o aço e o concreto, denominado adesivo químico. Em geral, os adesivos químicos são disponíveis em cápsulas, cartuchos ou sistemas de injeção contendo compostos orgânicos, inorgânicos ou uma mistura destes [4].

Neste trabalho foi abordado o estudo de ancoragens químicas em que o furo não excede 1,5 vezes o diâmetro da barra. Nos casos em que o furo excede estas dimensões, a camada de resina entre o concreto e a barra de aço torna-se excessivamente espessa, o que afeta o comportamento da ancoragem como um todo [5].

A ancoragem química (conjunto da barra de aço e adesivo químico) apresenta comportamento de transferência de forças similar ao de barras concretadas monoliticamente. A capacidade de transferência de forças em ancoragens químicas é determinada pela resistência do adesivo químico às forças concentradas impostas pelas nervuras da barra de aço e pela eficácia na transferência de forças na interface entre o adesivo e o concreto [5].

De acordo com COOK et al. [6], diversos fatores podem influenciar na resistência de ancoragens químicas em barras submetidas à tração em concreto não fissurado, tais como:

- Adesão do adesivo químico: a força de adesão depende do produto utilizado e não pode ser generalizada, ou seja, varia de um produto para o outro;

- Resistência do concreto: a resistência à adesão cresce pouco em concreto com resistências de $20 \mathrm{a}$ $40 \mathrm{MPa}$ e decresce em concretos a partir de $60 \mathrm{MPa}$, dependendo do produto, no entanto, as mudanças não são muito significativas;

- Limpeza do furo: também é uma característica do produto, mas ensaios mostraram que no caso de um furo não estar limpo adequadamente alguns produtos apresentam reduções de até $80 \%$ na adesão resistente em comparação com a instalação do furo limpo;

- Temperatura e retração: alguns tipos de adesivo químico apresentam desempenho muito inferior quando submetidos a elevadas temperaturas e também em situação em que a retração é muito acentuada.

A fissuração do concreto reduz significativamente a resistência da ancoragem em relação ao concreto não fissurado, esta redução varia de acordo com o tipo de adesivo químico.

De acordo com os estudos realizados em COOK et al. [6], podem ser descritos cinco principais modos de falha: no cone de concreto, interface adesivo/concreto, interface barra/adesivo, falha simultânea nas interfaces adesivo/concreto e adesivo/barra e ruptura da barra de aço, como pode ser observado na Figura 2.

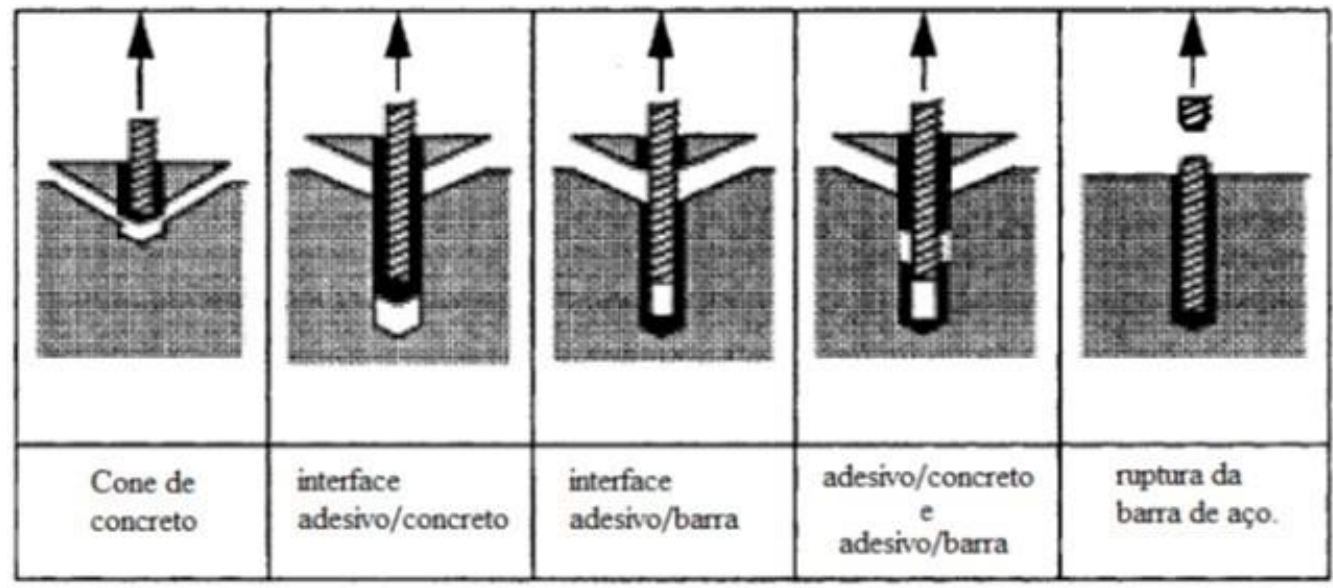

Figura 2: Modos de ruptura de ancoragem química. (Fonte: adaptado de Cook et al. [6])

Barras inseridas a uma profundidade de 3 a 5 vezes o diâmetro da mesma têm ruptura caracterizada pela formação de um cone de concreto com inclinação de $35^{\circ}$ em relação à superfície de concreto. Para maiores profundidades a ruptura acontece de forma mista entre arrancamento e cone de concreto. $\mathrm{O}$ cone de con- 
creto se forma na superfície a uma distância de 3 a 5 diâmetros. No caso de um grupo de barras, o espaçamento entre elas é determinante no modo de ruptura. Com um espaçamento pequeno as barras formam um único cone de ruptura, do contrário, com espaçamento suficiente, têm cones de ruptura separados [4].

A curva de força versus deslocamento de barras instaladas com auxílio de adesivo químico, em situação de ruptura por arrancamento, depende da rigidez e adesão do adesivo químico e também da superfície de ruptura. Ao se utilizar um adesivo rígido com uma adesão adequada tem-se comportamento praticamente linear até próximo da carga máxima. O comportamento após atingir a carga máxima no ensaio depende de qual superfície atingiu a ruptura.

ELIGEHAUSEN et al. [4] apresentaram curvas de força versus deslocamento obtidas em ensaios de arranchamento de barras com adesivos químicos, ilustradas na Figura 3. A curva de força versus deslocamento de barras instaladas com auxílio de adesivo químico, em situação de ruptura por arrancamento, depende da rigidez e adesão do adesivo químico e também da superfície de ruptura. Ao se utilizar um adesivo rígido com uma adesão adequada tem-se comportamento praticamente linear até próximo da carga máxima. O compor-

tamento após atingir a carga máxima no ensaio depende de qual superfície atingiu a ruptura.

Segundo ELIGEHAUSEN et al. [4], em caso de ruptura entre o adesivo e o concreto, a barra encontra-se em um meio rugoso e o atrito é mobilizado. Se a capacidade resistente do atrito é menor que a adesão proporcionada pelo adesivo químico a resistência cai. Geralmente, mesmo menor que a adesão, este atrito é suficiente para proporcionar ruptura com certa ductilidade, ou seja, não há uma queda brusca na resistência com o aumento do deslocamento, como pode ser observado no gráfico A da Figura 3.Caso o atrito mobilizado seja maior que a adesão, a força resistente cresce até que o atrito atinja seu limite, como pode ser observado no gráfico B da Figura 3. Quando a ruptura se dá entre a interface do adesivo e a barra de aço, o sistema atinge sua força máxima e logo cai, uma vez que a superfície formada pelo adesivo que envolve a barra é lisa e não têm a capacidade de gerar atrito suficiente para evitar a queda acentuada da força resistente, como pode ser observado no gráfico C da Figura 3. De acordo com ELIGEHAUSEN et al. [4], uma ruptura dúctil é mais interessante, pois possibilita a redistribuição das forças em um grupo de ancoragens.
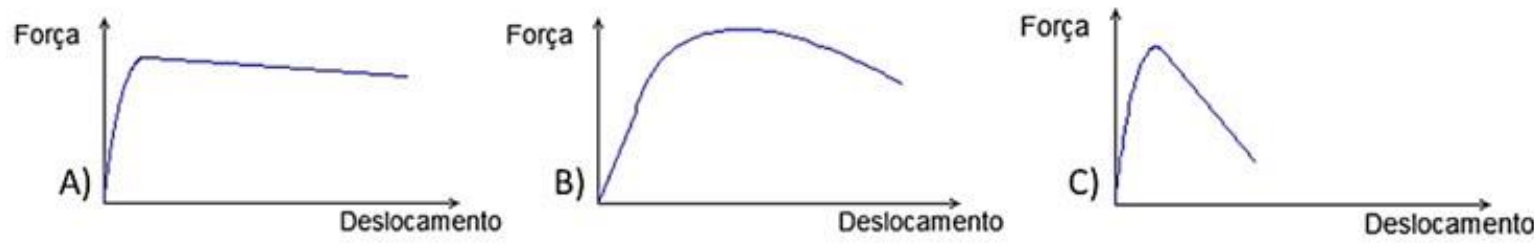

Figura 3: Curvas forças versus deslocamentos de ensaios de arrancamento de barras com adesivo químico. A) Caso em que a ruptura ocorre na interface adesivo-concreto, com o atrito menor que a adesão -; B) Caso em que a ruptura ocorre na interface adesivo-concreto, com o atrito maior que a adesão -; C) Caso em que a ruptura ocorre na interface adesivo barra de aço. (Fonte: adaptado de Eligehausen et al. [4])

\subsection{Diretrizes de projeto e prescrições normativas}

A normatização das ancoragens químicas é muito difícil, pois há uma grande variedade existente no mercado, que possuem diferentes características e múltiplos propósitos. É notável que o modo de instalação e o meio em que a ancoragem será instalada podem modificar sensivelmente seu comportamento. No Brasil, mesmo com vasta utilização, não há normatização ou regulação destes produtos.

De acordo com MAHRENHOLTZ [7], na Europa e nos Estados Unidos as construções, ou componentes de uma construção, devem ter sua durabilidade e segurança asseguradas de acordo com as leis vigentes de construção civil, o que é garantido por um dos meios a seguir:

- Projeto e construção de acordo com uma norma vigente;

- Projeto e construção com aprovação técnica individual de uma autoridade da construção civil, ou seja, são elaborados critérios e ensaios específicos para um único projeto e construção;

- Projeto e construção com aprovação técnica generalizada de uma autoridade da construção civil, neste caso existem critérios e ensaios pré-determinados pela autoridade que asseguram segurança e durabilidade para uma certa gama de utilizações.

A aprovação técnica só é válida no caso de inexistência de normas e a elaboração de aprovações técnicas individuais é cara e trabalhosa, pois exige uma avaliação caso a caso. Então, para produtos muito utilizados, como ancoragens, são empregadas aprovações técnicas generalizadas, ou seja, é definido um docu- 
mento com diretrizes de qualificação técnica que especifica os ensaios e pré-requisitos para a obtenção da aprovação técnica. O programa experimental é realizado a fim de certificar a qualidade, durabilidade e determinar as resistências características e dados de projeto.

O documento que descreve o programa experimental chama-se "Diretriz de qualificação" e geralmente está vinculado a uma norma. Nos EUA, o ACI 355.4 [8] prescreve o procedimento de ensaios e fornece os dados relevantes para o projeto de acordo com o ACI-318-14 [9]. Na Europa, o processo de qualificação é descrito pelas EOTA TR-023 [10] e EOTA TR-029 [11] e deve ser utilizado em conjunto com o Eurocode 2.

O mecanismo de transferência de força das ancoragens químicas qualificadas é geralmente semelhante as armaduras em concreto armado, entretanto, a grande questão no projeto da ancoragem é saber quando isto pode ser considerado.

Em ACI-318-14 [9] (capítulo 17 e capítulo 24) são apresentados dois diferentes métodos de cálculo para ancoragens químicas. O capítulo 24.apresenta o método para o cálculo do comprimento de desenvolvimento das armaduras em concreto armado, e então, é possível utilizar este equacionamento empregando a resistência de aderência característica obtida nos ensaios experimentais de qualificação para calcular a profundidade da ancoragem química. O comprimento de desenvolvimento é o comprimento necessário para que a barra alcance sua máxima capacidade sem que ocorra escorregamento entre a barra e o concreto. O capítulo 17 apresenta um método de cálculo, baseado no CCD (Concrete Capacity Design method) que considera a ruptura cônica e a falha por arrancamento [12].

Na Europa é semelhante, a EOTA TR-023 [10] é uma diretriz de qualificação que recomenda um método de dimensionamento baseado no comprimento de ancoragem de armaduras em concreto armado determinado pelo EUROCODE 2 [13]. E o EOTA TR-029 [11] propõe um método de cálculo baseado no CCD.

\section{MATERIAIS E MÉTODOS}

Neste item são apresentados os modelos ensaiados, a caracterização dos materiais empregados nos modelos e os ensaios experimentais realizados.

\subsection{Confecção dos modelos}

Foram fabricados três modelos de acordo com as características descritas na Tabela 1.

Tabela 1: Caracterização dos modelos fabricados para os ensaios.

\begin{tabular}{cccc}
\hline MODELO & DESCRIÇÃo & ANCORAGEM & COMPRIMENTO DE ANCORAGEM \\
\hline A & Monolítico & Gancho $90^{\circ}$ & Conforme NBR 6118 [2] $-25 \mathrm{~cm}$ \\
\hline B & Pós-instalado & Reta com ancoragem química & Conforme NBR 6118 [2] $-25 \mathrm{~cm}$ \\
\hline C & Pós-instalado & Reta com ancoragem química & $\begin{array}{c}\text { Conforme especificação do fabri- } \\
\text { cante do adesivo químico }-20 \mathrm{~cm}\end{array}$ \\
\hline
\end{tabular}

O Modelo A tem a principal função de servir como referência nos ensaios. O dimensionamento e o detalhamento deste consolo foram feitos seguindo as prescrições das normas NBR 9062 [3] e NBR 6118 [2], portanto considera-se que este consolo tem a segurança requerida pelas referidas normas. A intenção foi comparar o desempenho dos Modelos B e C com o modelo A por meio da curva força versus deslocamento, da força máxima resistente, do quadro de fissuração desenvolvido e do modo de ruptura.

A única diferença entre A e B é o método de ancoragem: o Modelo A apresenta gancho e o Modelo B utiliza ancoragem química. Desta forma, é possível isolar a variável "método de ancoragem" e avaliar sua influência no comportamento da solução proposta, bem como a segurança quando comparado ao Modelo A. O Modelo C apresenta o comprimento de ancoragem recomendado pelo fabricante do adesivo químico. As recomendações do fabricante foram avaliadas face ao comportamento do Modelo A, enquanto que a influência da variação do comprimento de ancoragem foi feita a partir de comparações com o Modelo B.

Nos modelos foram adotados pilares curtos com o intuito de reduzir o efeito de flexão. A seção transversal correspondeu a $40 \mathrm{~cm}$ x $40 \mathrm{~cm}$ e foi projetada uma sapata para garantir o equilíbrio do modelo. Os consolos utilizados apresentaram dimensões de $25 \mathrm{~cm}$ de altura x $30 \mathrm{~cm}$ de comprimento, resultando em uma relação a/d de aproximadamente 0,8 (consolo curto). Os modelos foram projetados para romper por flexão, com escoamento da armadura do tirante principal.

Os modelos foram fornecidos por uma empresa de pré-moldados e todos concretados na mesma data. 
A sequência de fabricação dos modelos pode ser observada na Figura 4.

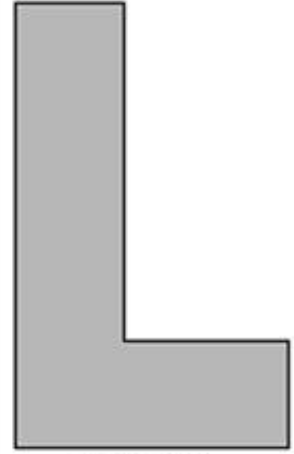

etopo 1

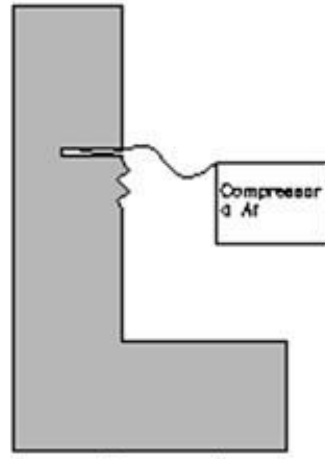

etapo 4

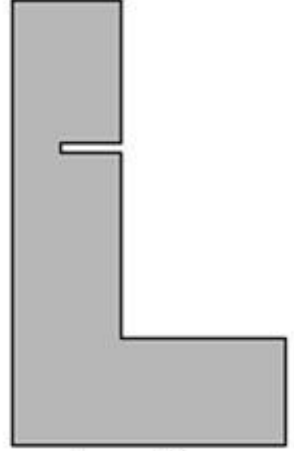

etapa 2

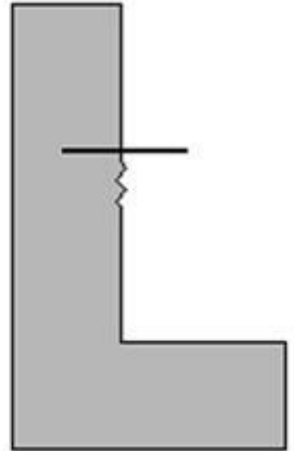

etapa 5

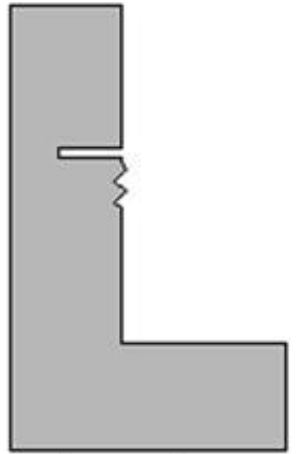

etapo 3

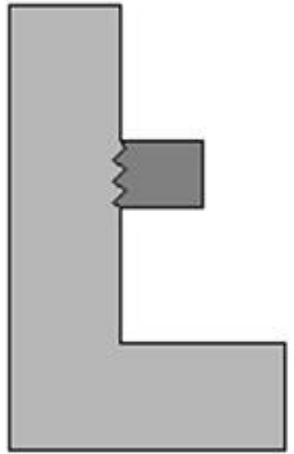

etapa 6

Figura 4: Sequência de execução das peças

A sequência de fabricação dos modelos é composta pelas seguintes etapas: 1- Concretagem da peça; 2- Execução dos furos; 3- Escarificação do concreto; 4- Limpeza do furo com compressor a ar; 5- Injeção do adesivo químico e colocação das barras; 6- Concretagem do consolo.

Na Figura 5 pode-se observar a forma e a armação dos modelos antes da concretagem.
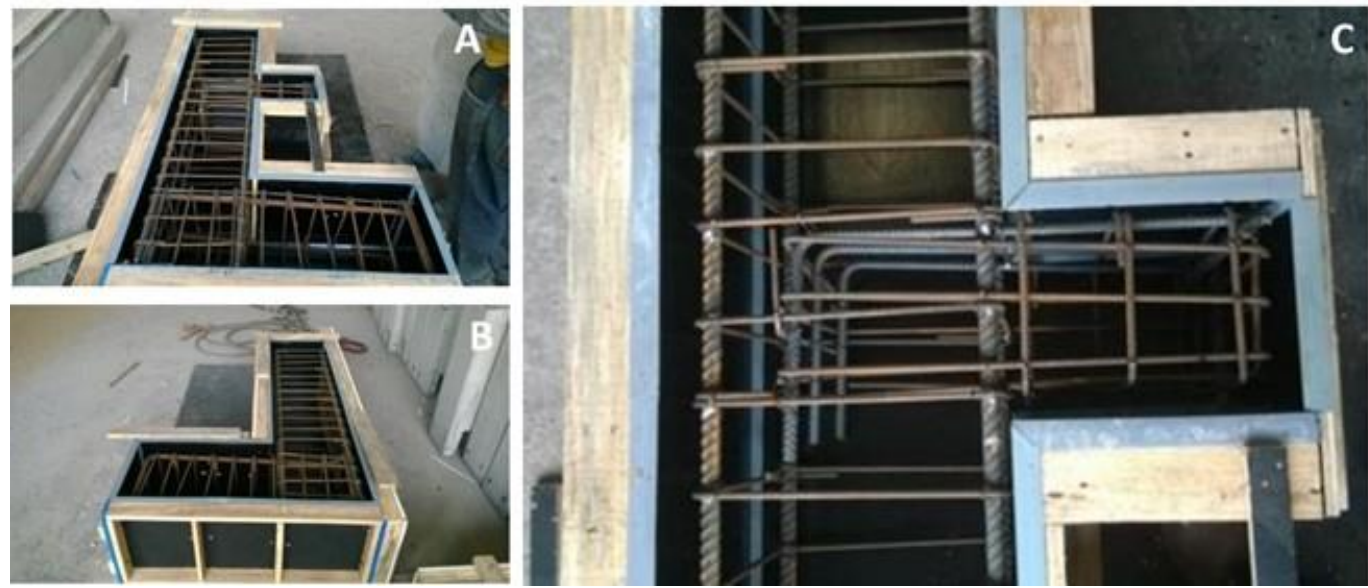

Figura 5: A) Forma e armação do modelo A; B) Forma e armação dos modelos B e C; C) Detalhe do recorte na forma e da armação do consolo.

Na Figura 5 C), pode-se observar um detalhe que ilustra claramente o congestionamento de armaduras na região do consolo e o recorte na forma que impossibilita o seu reaproveitamento.

Os furos foram executados por meio de um martelo pneumático, sendo feito em seguida o apicoamento do concreto. Após a limpeza desta região, realizou-se a montagem da armadura do consolo, com o empre- 
go do adesivo químico, e posterior concretagem do consolo, como pode ser observado na Figura 6.
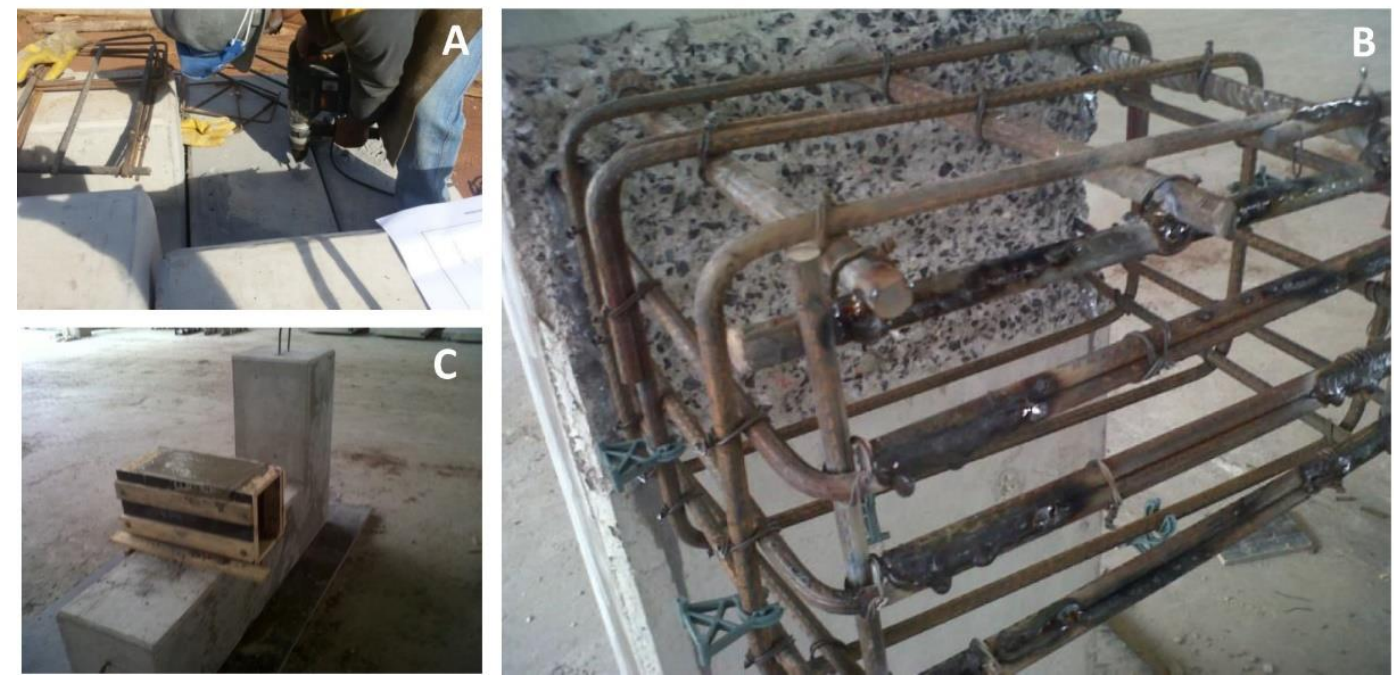

Figura 6: Etapas da fabricação dos modelos. A) Execução dos furos; B) Escarificação do concreto, montagem da armadura do consolo; C) Concretagem do consolo.

\subsection{Caracterização dos materiais empregados nos modelos}

Os materiais empregados nos modelos corresponderam ao concreto, a armadura e o adesivo químico, cujas características são descritas na Tabela 2.

Tabela 2: Caracterização dos materiais empregados nos modelos.

\begin{tabular}{ll}
\hline MATERIAL & CARACTERÍSTICAS \\
\hline Concreto & O concreto utilizado possuiu relação água/cimento igual a 0,41. O modelo A foi concretado \\
& com o mesmo lote de concreto dos modelos B e C, o qual apresentou resistência média à com- \\
& pressão aos 28 dias igual a $59 \mathrm{MPa}$. Os consolos dos modelos B e C foram concretados juntos \\
& em outra data e apresentaram resistência à compressão média aos 28 dias igual a $64 \mathrm{MPa}$. \\
& Na data dos ensaios o modelo A e os pilares dos modelos B e C apresentaram resistência à \\
& compressão estimada em $67 \mathrm{MPa}$. Para os consolos dos modelos B e C, a resistência à com- \\
& pressão foi estimada em 70 MPa. \\
\hline Armadura & A armação do tirante principal dos consolos foi composta por barras nervuradas de 12,5 mm, \\
& aço CA-50 com resistência ao escoamento igual a 556 MPa, de acordo com relatório fornecido \\
& pelo fabricante das peças. \\
\hline Adesivo químico & O adesivo químico utilizado correspondeu a um adesivo de injeção para múltiplos tipos de \\
& instalação e possuiu adesão média igual a $15 \mathrm{MPa}$ de baixa retração para uso em concreto fis- \\
& surado ou não. \\
\hline
\end{tabular}

\subsection{Ensaios experimentais}

Os ensaios experimentais foram realizados com a aplicação de uma força, por meio de um atuador hidráulico, a cerca de $20 \mathrm{~cm}$ da face do pilar. O monitoramento da força aplicada foi feito por meio de célula de carga. Além disso, foram empregados dois clinômetros, posicionados no centro geométrico do consolo, um em cada face lateral, para a medida do giro do consolo. Um terceiro clinômetro foi posicionado no pilar de forma alinhada com o clinômetro fixado no consolo, para o registro da medida do giro do pilar, possibilitando, assim, a obtenção da medida do giro relativo entre o consolo e o pilar. Na Figura 7 é possível observar o esquema de ensaio e a instrumentação dos modelos. 

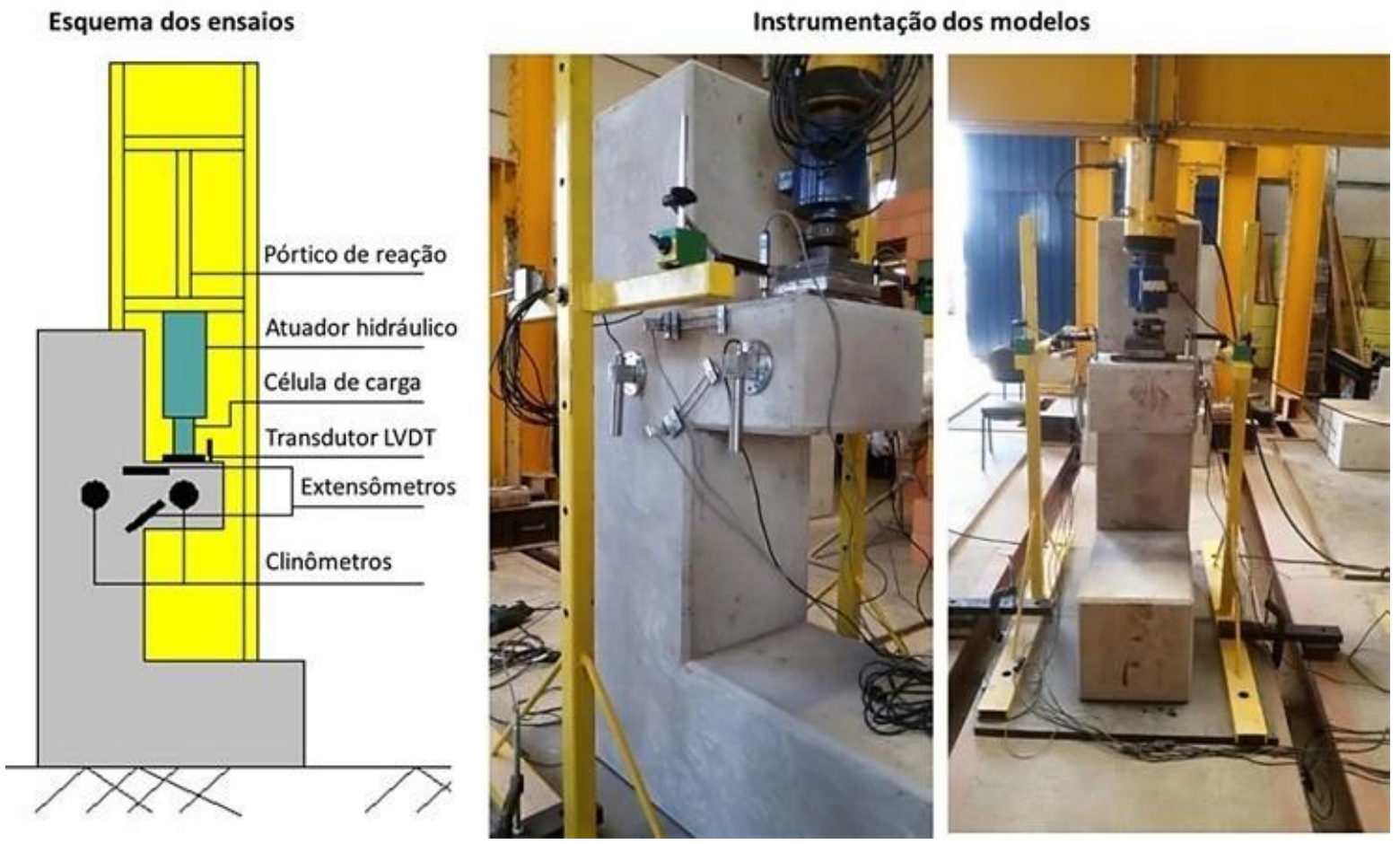

Figura 7: Esquema dos ensaios e instrumentação empregada nos modelos.

Ademais, nas duas faces laterais do consolo foram colocados extensômetros elétricos de base removível no nível da armadura do tirante e também inclinados, aproximadamente, na inclinação da biela para a obtenção de medidas de deslocamento relativo. Foram posicionados transdutores no consolo para a medição de deslocamentos lineares. Todos os instrumentos empregados nos ensaios foram conectados a um sistema de aquisição de dados System 5000 da Vishay, que permitiu o registro das diversas medições.

\section{RESULTADOS E DISCUSSÕES}

A seguir são apresentados os principais resultados e discussões dos ensaios experimentais realizados. Maiores detalhes sobre os ensaios e as análises experimentais podem ser encontrados em DAMASCENO [14].

\subsection{Modelos ensaiados}

A primeira fissura do modelo A ocorreu com aproximadamente $140 \mathrm{kN}$. O modelo atingiu a carga de $400 \mathrm{kN}$ com uma fissura de flexão bem desenvolvida e então ocorreu o fendilhamento da biela. A abertura de fissuras no momento da ruptura foi de $1,3 \mathrm{~mm}$.

O modelo B teve a primeira fissura com o carregamento próximo a $70 \mathrm{kN}$. Atingiu a carga de $340 \mathrm{kN}$ com uma fissura típica de flexão bem desenvolvida com abertura em torno de 5,5 mm e com o surgimento de uma segunda fissura de flexão. Para um carregamento de $300 \mathrm{kN}$ formou-se uma fissura inclinada no pilar. O ensaio foi interrompido por questões de segurança.

A primeira fissura no modelo $\mathrm{C}$ surgiu com o carregamento próximo a $80 \mathrm{kN}$, e, assim como nos modelos A e B, desenvolveu-se uma fissura típica de flexão. O modelo atingiu a carga de $377 \mathrm{kN}$ com uma abertura de fissura de $5 \mathrm{~mm}$. Para uma carga de $290 \mathrm{kN}$ surgiu uma fissura inclinada no pilar. Durante este ensaio foi feito um ciclo de carregamento e descarregamento próximo a carga de $150 \mathrm{kN}$ para avaliar o comportamento do consolo mediante esta solicitação; o comportamento foi satisfatório uma vez que toda a deformação foi recuperada. Da mesma forma que no modelo B, o ensaio também foi interrompido.

Na Figura 8 pode-se observar a ruptura do modelo A, o modelo B após o ensaio e as fissuras citadas e a ruptura do modelo $\mathrm{C}$. 

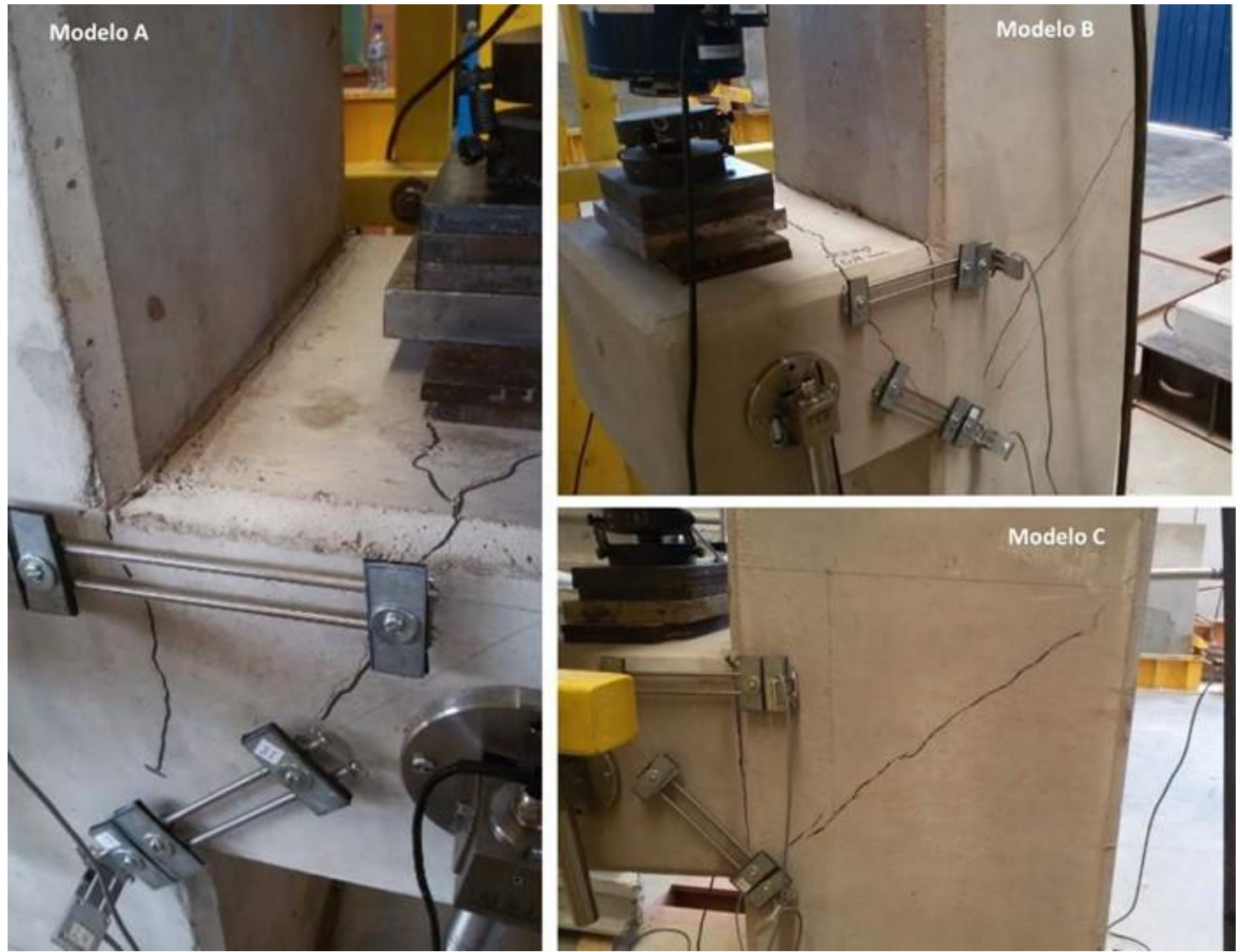

Figura 8: Modelos após os ensaios experimentais: ruptura do modelo A; modelo B após o ensaio e ruptura do modelo C.

Todos os modelos romperam por flexão como previsto em projeto. $\mathrm{O}$ modelo $\mathrm{A}$ apresentou fissuras de fendilhamento do concreto apenas depois de uma grande abertura da fissura de flexão, portanto pode-se considerar que o estado limite último atingido primeiro foi o de fissuração excessiva. Na Tabela 3 são apresentados os valores previstos de resistência para os modelos e a relação entre os valores experimentais e os valores previstos teoricamente.

Tabela 3: Resultados experimentais e teóricos para os modelos ensaiados.

\begin{tabular}{cccc}
\hline MODELO & NBR 9062 [14] & EXPERIMENTAL & EXPERIMENTAL / NBR 9062 [14] \\
\hline A & $216,0 \mathrm{kN}$ & $400,0 \mathrm{kN}$ & 1,85 \\
\hline B & $216,0 \mathrm{kN}$ & $340,0 \mathrm{kN}$ & 1,57 \\
\hline C & $221,5 \mathrm{kN}$ & $377,0 \mathrm{kN}$ & 1,70 \\
\hline MÉDIA & $\mathbf{2 1 7 , 8 3 ~ k N}$ & $\mathbf{3 7 2 , 3 3 ~ k N}$ & $\mathbf{1 , 7 1}$ \\
\hline
\end{tabular}

Os valores dos ensaios se apresentaram sempre superiores aos valores previstos teoricamente, variando de 1,57 a 1,85 vezes. Este fato pode ser explicado pelo endurecimento do aço e ganho de resistência após o patamar de escoamento, não considerado no cálculo e também pela contribuição da armadura de costura na flexão.

Na Figura 9, Figura 10 e Figura 11 são comparadas as curvas dos clinômetros, transdutores e extensômetros, respectivamente, para os três modelos. Os resultados dos clinômetros no pilar serão omitidos no gráfico dos clinômetros, pois em todos os casos o pilar apresentou rotações insignificantes. Dessa forma, podemos supor que o consolo teve comportamento de corpo rígido e que a rotação medida pelo clinômetro posicionado no consolo foi praticamente a rotação relativa entre o pilar e o consolo. 


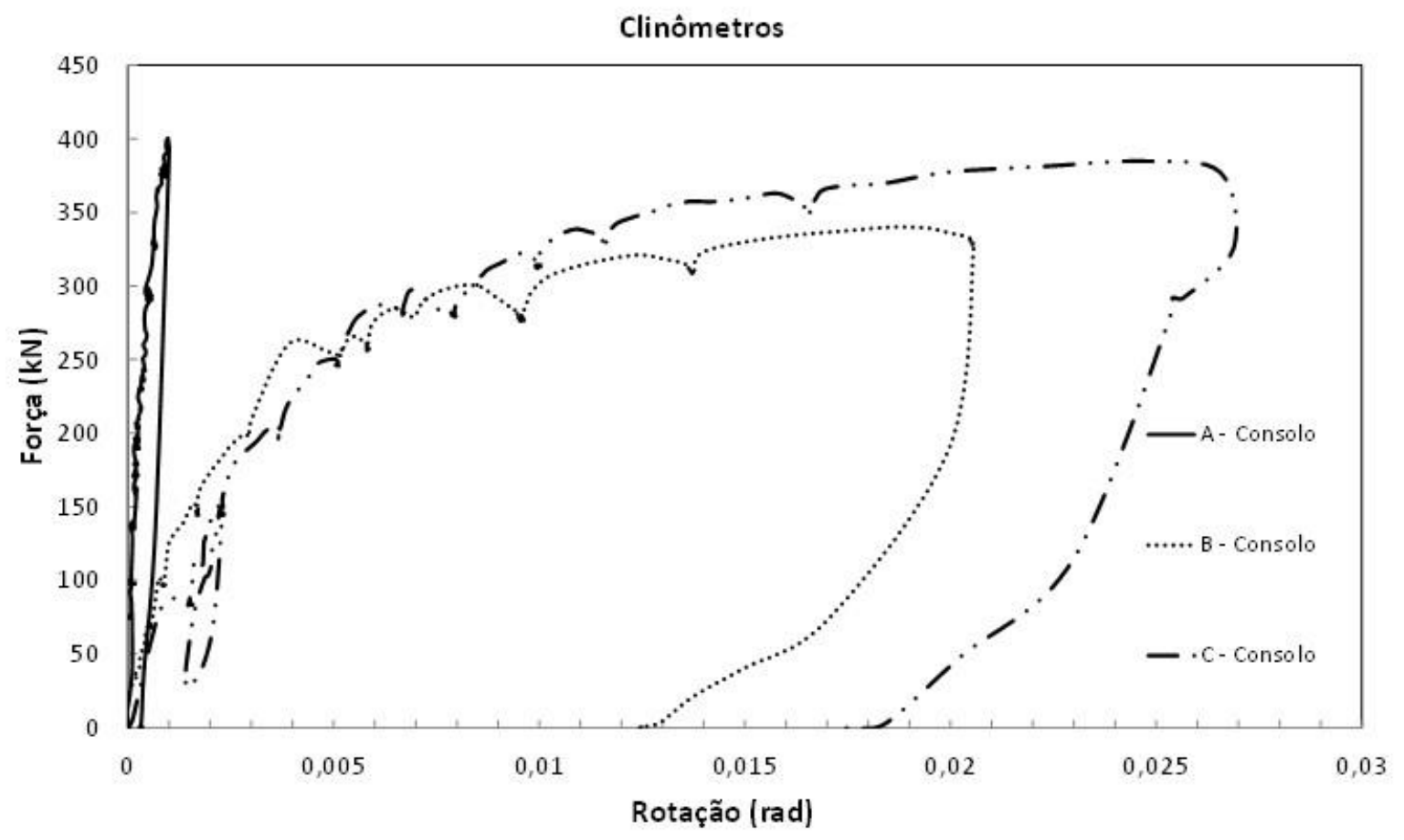

Figura 9: Comparação entre as medidas dos clinômetros posicionados nos consolos.

As medidas dos clinômetros mostram que o modelo A apresentou rotações menores em relação aos modelos com consolo pós-instalado, cerca de 20 e 27 vezes menor para as cargas máximas do que o modelo monolítico, considerando o modelo $\mathrm{B}$ e $\mathrm{C}$ respectivamente, o que evidencia um claro comportamento mais rígido da peça monolítica. Os modelos $\mathrm{B}$ e $\mathrm{C}$ apresentaram medidas de rotações próximas durante todo o ensaio, indicando que o comprimento de ancoragem não apresentou influência nas rotações dos modelos

\section{Transdutores}

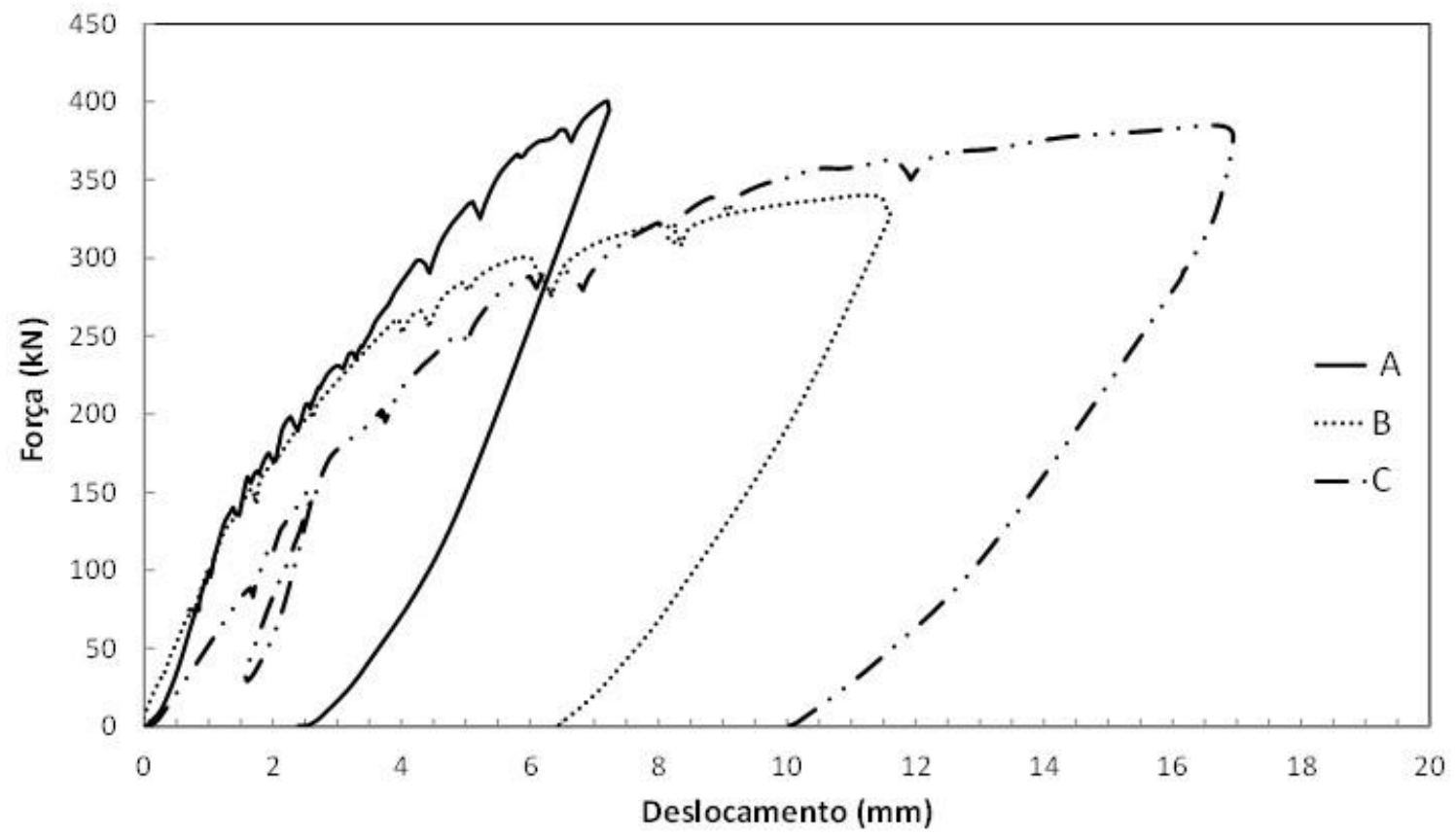

Figura 10: Comparação entre as medidas dos transdutores.

Os transdutores apresentaram nos modelos A e B medidas próximas até o carregamento de aproximadamente $230 \mathrm{kN}$, quando, então, a curva do modelo A se diferencia das demais e apresentou comportamento mais rígido. $\mathrm{O}$ modelo $\mathrm{C}$ apresenta deslocamentos maiores que os demais até aproximadamente $250 \mathrm{kN}$, a 
partir deste nível de carregamento segue com deslocamentos próximos ao do modelo B. As medidas dos transdutores apresentam uma diferença de rigidez menor entre os modelos em comparação com a medida dos clinômetros, isto se deve ao fato da medida do transdutor ser uma medida global, ou seja, imperfeições na peça de concreto podem afetar as medidas dos transdutores. Apesar destes fatores, as medidas dos transdutores estão coerentes com os demais instrumentos e apresentam o comportamento mais rígido da peça monolítica (modelo A ).

\section{Extensômetro na linha do tirante}

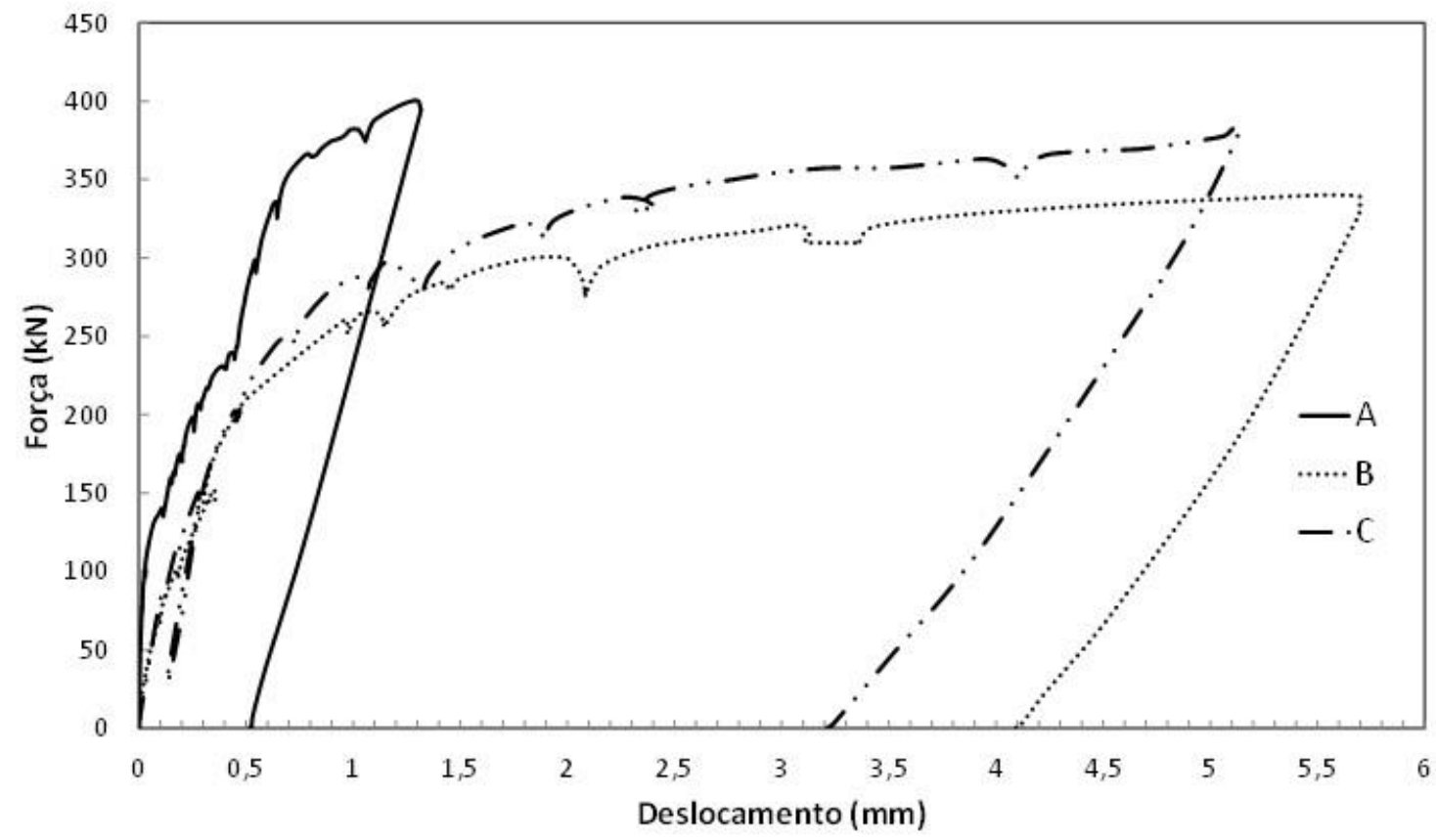

Figura 11: Comparação entre as medidas dos extensômetros elétricos de base removível.

Os extensômetros na linha do tirante apresentaram medidas diretas da abertura de fissuras de flexão, sendo obtido valores para a carga final correspondente a $1,3 \mathrm{~mm}$ para o modelo A (em $400 \mathrm{kN}$ ), 5,5 mm para o modelo B (em $340 \mathrm{kN})$ e 5,0 mm para o modelo C (em $377 \mathrm{kN})$. Assim, observou-se que o modelo monolítico apresentou abertura de fissuras inferior aos valores obtidos nos modelos com consolo pós-instalado. É importante notar que isto também aconteceu nos modelos com consolo pós-instalados ensaiados por BELLUCIO e EL DEBS [15] e COSTA [16]. O comprimento de ancoragem também não influenciou na abertura de fissuras, uma vez que os modelos com consolo pós-instalados (B e C) tiveram medidas próximas de abertura de fissuras. Uma hipótese para explicar o fato de consolos pós-instalados (B e C) apresentarem abertura de fissuras maiores do que o consolo monolítico é a presença da junta de concretagem entre o pilar e o consolo. Os modelos B e C apresentaram a primeira fissura com cargas de 70 e $80 \mathrm{kN}$ respectivamente, ambas situadas na região da junta de concretagem, enquanto que a primeira fissura do modelo monolítico surge com $150 \mathrm{kN}$. A junta de concretagem é uma região que apresenta uma resistência ao cisalhamento e à tração reduzidas, fato que se confirmou na abertura da primeira fissura dos modelos $\mathrm{B}$ e $\mathrm{C}$, e isto pode acarretar maiores deslocamentos nos modelos com consolos pós-instalados. Esta hipótese também explica a maior abertura de fissuras nos modelos de BELLUCIO e EL DEBS [15] e COSTA [16].

As medidas dos clinômetros, dos transdutores e extensômetros indicam uma ruptura de forma dúctil, com grandes deformações dos modelos com consolo pós-instalado (modelos B e C). Nenhum modelo apresentou escorregamento da armadura, todos os modelos romperam pelo escoamento do tirante, de forma dúctil.

Aplicando os coeficientes de segurança $\gamma_{C}=1,4$, e $\gamma \mathrm{s}=1,15$ aos valores previstos pela NBR 9062 [3], tem-se uma carga de projeto de aproximadamente $190 \mathrm{kN}$. Supondo que no carregamento de projeto está aplicado um $\gamma_{\mathrm{f}}=1,4$, pode-se estimar o carregamento de serviço de $136 \mathrm{kN}$. Desta forma, é possível avaliar a abertura de fissuras dos modelos para o carregamento de projeto e de serviço. A Tabela 4 apresenta a abertura de fissuras para estes níveis de carregamento e traz os limites de abertura de fissuras de acordo com a NBR 6118 [2] para o nível de carregamento de serviço. 
Tabela 4: Resultados experimentais de abertura de fissuras e limites prescritos pela NBR 6118 [2].

\begin{tabular}{ccc|c}
\hline \multicolumn{2}{c|}{ RESULTADOS EXPERIMENTAIS } & \multirow{2}{*}{ LIMITES PRESCRITOS PELA NBR 6118 [2] } \\
\cline { 1 - 2 } MODELO & \multicolumn{2}{c}{ CARREGAMENTO } & \multirow{2}{*}{ LIMITE DE ABERTURA DE FISSURAS } \\
\cline { 1 - 2 } A & $0,11 \mathrm{~mm}$ & $0,26 \mathrm{~mm}$ & Classe de agressividade I $-0,4 \mathrm{~mm}$ \\
\hline B & $0,29 \mathrm{~mm}$ & $0,41 \mathrm{~mm}$ & Classe de agressividade II e III $-0,3 \mathrm{~mm}$ \\
\cline { 1 - 2 } C & $0,24 \mathrm{~mm}$ & $0,40 \mathrm{~mm}$ & Classe de agressividade IV $-0,2 \mathrm{~mm}$ \\
\hline
\end{tabular}

O consolo monolítico apresentou abertura de fissuras abaixo dos limites exigidos para todas as classes de agressividade ambiental. Os modelos com consolo pós-instalado apresentaram abertura de fissuras abaixo dos limites para as classes de agressividade ambiental I, II e III e acima do limite da classe IV.

Não se observou escorregamento da armadura do tirante nos modelos com consolo instalado com auxílio de adesivo químico, portanto o adesivo químico mostrou comportamento adequado e resistência em ambos os modelos.

$\mathrm{O}$ aparecimento da fissura inclinada no pilar nos modelos $\mathrm{B}$ e $\mathrm{C}$ atenta para o aparecimento de tensões de tração no pilar na região da ancoragem, correspondendo a uma evidência que o modelo de bielas e tirantes pode ser adequado para este tipo de avaliação.

\section{CONCLUSÕES}

Com este trabalho conclui-se que a normatização e o estabelecimento de ensaios de qualificação técnica de ancoragens químicas para o uso com fins estruturais são de suma importância para a segurança das estruturas que fazem uso das mesmas.

A partir dos estudos experimentais pôde-se observar que o aparecimento de fissuras na região do pilar nos modelos com consolo pós-instalado mostrou que o equilíbrio entre bielas e tirantes na região da ancoragem se deu de forma diferente do que no caso do consolo monolítico, em que o tirante é ancorado com gancho. Os modelos com consolo pós-instalado apresentaram rigidez inferior e carga última ligeiramente menor $(377 \mathrm{kN}$ e $340 \mathrm{kN})$ que o consolo monolítico $(400 \mathrm{kN})$, no entanto, ainda acima dos valores previstos teoricamente. Além disso, os modelos com consolo pós-instalado apresentaram abertura de fissuras maior que o modelo com consolo monolítico, ainda assim abaixo que os limites estabelecidos pela NBR 6118 [2] para classes de agressividade ambiental I, II e III.

Não houve diferenças significativas no comportamento entre os modelos com consolo pós-instalado (B e C), indicando que a variação do comprimento de ancoragem de $25 \mathrm{~cm}$ para $20 \mathrm{~cm}$ não teve influência no comportamento estrutural.

Assim, as evidências indicam que a alternativa de consolo pós-instalado com auxílio de ancoragem química apresentou comportamento estrutural satisfatório quando solicitado por carregamento monotônico de curta duração, alcançando carga ligeiramente menor que o consolo monolítico de forma dúctil.

O aparecimento da fissura no pilar atenta para uma nova distribuição de tensões na região da ancoragem do tirante. Tal comportamento é compatível ao modelo de bielas e tirantes que evidencia o surgimento de tensões de tração na região da ancoragem. Para combater estas tensões de tração, sugere-se que sejam feitos ensaios com estribos na região próxima da ancoragem do tirante para avaliar a efetividade desta medida.

O comportamento para o carregamento em serviço também foi satisfatório, entretanto, são necessários maiores estudos no sentido de reduzir a abertura de fissura na interface consolo-pilar.

\section{AGRADECIMENTOS}

Os autores agradecem todas as instituições que tornaram esta pesquisa possível. À Usicon Construções Préfabricadas pela doação dos modelos. Å FAPESP pelos equipamentos utilizados no laboratório do NETPRE. Ao NETPre pela infraestrutura, pessoal técnico para os ensaios e materiais disponibilizados.

\section{BIBLIOGRAFIA}

[1] HILTI POST INSTALLED REBAR CONNECTIONS MANUAL B 2.11, Hilti Corp., 69 p, https://www.hilti.pt/content/dam/documents/pdf/e2/engineering/c-rebar/Technical_manual_rebar_EN.pdf. Acessado em julho de 2017. 
[2] ASSOCIAÇÃO BRASILEIRA DE NORMAS TÉCNICAS, NBR 6118: Projeto de estruturas de concreto - Procedimento. Rio de Janeiro, 2014.

[3] ASSOCIAÇÃO BRASILEIRA DE NORMAS TÉCNICAS (ABNT), NBR 9062 - Projeto e execução de estruturas de concreto pré-moldado, Rio de Janeiro, 2006.

[4] ELIGEHAUSEN, R.; MALLÉE, R.; AND SILVA, J. Anchorage in Concrete Construction, Ernst \& Sohn, Berlin, Germany, 2006.

[5] HAMAD, B.S., HAMMOUD,R.A., KUNZ,J. "Evaluation of Bond Strength of Bonded-In or PostInstalled Reinforcement", ACI Structural Journal, v. 103, n. 2, pp. 207-218, 2006.

[6] COOK, R., KUNZ, J., FUCHS, W., et al., "Behavior and Design of Adhesive Anchors under Tensile Load in Uncracked Concrete", ACI Structural Journal, v. 95, n. 1,pp. 9-26, Jan.-Feb. 1998

[7] MARENHOLTZ, P. Experimental Performance and Recom-mendations for Qualification of Postinstalled Anchors for Seismic Applications., Doctoral thesis, University of Stuttgart, Stuttgart, Germany, 343 pp, 2012.

[8] AMERICAN CONCRETE INSTITUTE (ACI). Committee 355. Qualification of Post-Installed Ad-hesive Anchors in Concrete (ACI 355.4-11) and Commentary, Farmington Hills, MI, 55 pp, 2011.

[9] AMERICAN CONCRETE INSTITUTE (ACI). Committee 318. Building Code Re-quirements for Structural Concrete (ACI 318-14) and Commentary (318R-14), Farmington Hills, Mich.,430 pp, 2005.

[10] TR023. Assessment of Post-Installed Rebar Connections. ETA Technical Report, European Organization for Technical Approvals (EOTA), Brussels, Belgium, 20 pp, 2006.

[11] TR029. Design of bonded anchors. ETA Technical Re-port, European Organization for Technical Approvals (EOTA), Brussels, Belgium, 36 pp, 2007.

[12] FUCHS, W., ELIGEHAUSEN, R., BREEN, J. E. "Concrete Capacity Design (CCD) Approach for Fastening to Concrete", ACI Structural Journal, V. 92, n. 1, pp. 73-94, Jan.-Feb. 1995

[13] EUROPEAN COMMITTEE FOR STANDARDIZATION, EUROCODE 2. EN 1992-1-1: Design of concrete structures - Part 1-1: General rules and rules for buildings, Brussels, 2004.

[14] DAMASCENO, J. H. L. Consolos instalados em etapa posterior à concretagem de pilar com auxílio de adesivo químico. 129f. Dissertação de M.Sc.,Universidade Federal de São Carlos, São Carlos, 2016.

[15] BELLUCIO, E. K., EL DEBS, M. K. "Proposta de execução de consolos moldados em etapa separada dos pilares pré-moldados", In: Anais do $3^{\circ}$ Encontro Nacional de Pesquisa-Projeto-Produção em Concreto pré-moldado, São Carlos, 2013.

[16] COSTA, J. B. Estudo Experimental de Consolos de Concreto com Fibras Moldados em Etapas Distintas dos Pilares. Dissertação M.Sc., Escola de Engenharia de São Carlos, São Carlos, 2009. 